\title{
Climate Change Impacts and Adaptation in Rainfed Farming Systems: A Modeling Framework for Scaling-Out Climate Smart Agriculture in Sub-Saharan Africa
}

\author{
Berhanu F. Alemaw ${ }^{1}$, Timothy Simalenga ${ }^{2}$ \\ ${ }^{1}$ Department of Geology, University of Botswana, Gaborone, Botswana \\ ${ }^{2}$ Centre for Coordination of Agricultural Research \& Development in Southern Africa (CCARDESA), Gaborone, \\ Botswana \\ Email: tsimalenga@ccardesa.org
}

Received 29 April 2015; accepted 14 August 2015; published 17 August 2015

Copyright (C) 2015 by authors and Scientific Research Publishing Inc.

This work is licensed under the Creative Commons Attribution International License (CC BY). http://creativecommons.org/licenses/by/4.0/

(c) (i) Open Access

\begin{abstract}
Improving agricultural water productivity, under rainfed or irrigated conditions, holds significant scope for addressing climate change vulnerability. It also offers adaptation capacity needs as well as water and food security in the southern African region. In this study, evidence for climate change impacts and adaptation strategies in rainfed agricultural systems is explored through modeling predictions of crop yield, soil moisture and excess water for potential harvesting. The study specifically presents the results of climate change impacts under rainfed conditions for maize, sorghum and sunflower using soil-water-crop model simulations, integrated based on daily inputs of rainfall and evapotranspiration disaggregated from GCM scenarios. The research targets a vast farming region dominated by heavy clay soils where rainfed agriculture is a dominant practice. The potential for improving soil water productivity and improved water harvesting have been explored as ways of climate change mitigation and adaptation measures. This can be utilized to explore and design appropriate conservation agriculture and adaptation practices in similar agro-ecological environments, and create opportunities for outscaling for much wider areas. The results of this study can suggest the need for possible policy refinements towards reducing vulnerability and adaptation to climate change in rainfed farming systems.
\end{abstract}

\section{Keywords}

Climate Change, Adaptation, Rainfed Farming Systems, A Modeling, Climate Smart Agriculture, Southern Africa 


\section{Introduction}

Climate change and other global drivers of socio-economic, energy, global trade, resources and demographic changes are set to affect present and future human development including the vulnerable areas such as southern Africa region (SADC) [1]. Faced with imperatives of increased food production and poverty alleviation, present day conditions call for high vigilance in developing and preserving the raw materials for food production, specifically through land and water management [2]. Faced with imperatives of increased food production and poverty alleviation, present day conditions call for high vigilance in developing and preserving the raw materials for food production: land and water. Agricultural water (under rainfed or irrigation settings) holds significant scope for addressing climate change vulnerability and adaptation needs as well as water and food insecurity in the region [1]-[3].

The observed human-induced changes to climate pose a threat to food security the world over [3] and Southern Africa is no exception. Climate model studies show that the average temperature of earth's surface is expected to increase by $3^{\circ} \mathrm{C}$ over the next century, if greenhouse gas emissions continue to rise at the current rates [3]. This has a negative impact on crop yields and food security in the Southern African region where $60 \%$ $80 \%$ of the population is directly dependent on agriculture for their livelihoods [2].

Crop and livestock production systems will have to change in response to the changing agro-ecological conditions. This manuscript aims at developing a set of practical approaches to agriculture in order for farmers to be resilient and adapt to the predicted climate changes. Here, a regional framework for the implementation of climate smart agriculture concepts is also illustrated.

The specific objective of this study is to inform adaptation policy making processes. Also it will support investment decisions in climate change adaptation. This paper seeks to inform scientists and experts in the fields of agriculture, climate change and socio-economics to collectively build a strong base of evidence on climate change and variability impacts on rainfed cropping systems. It also tries to devise agricultural interventions and practices that enhance general resilience in the quest to overcome climatic shocks and develop adaptation strategies.

The main objectives of this manuscript are to report, for a southern African study region, on agricultural impacts assessment under climate variability and change scenarios for rainfed systems to illustrate the regional challenges of climate change and variability in southern Africa. The research uses a selected study area, known as the Pandamatenga Plains, which is located in northern Botswana, and it considers cropping of maize, sorghum and sunflower under rainfed conditions.

The specific objectives are: 1) to show real world climate change through the scientific understanding of downscaled climate scenarios; 2) to integrate downscaled climate scenarios with a crop model and adaptation option models, and with agricultural production information; 3) to assess the impact of climate change on crop yield, soil moisture stress, excess runoff etc. in rainfed agricultural systems; 4) to determine the potential for excess moisture enhancement and water harvesting through a modeling study; and finally 5) to recommend adaptation strategies based on modeling evidences.

\section{Climate Change and Rainfed Crop Production}

The southern African region is vulnerable to climate change that causes multiple biophysical, political, and socioeconomic stresses. The stresses remain a major threat to the region's susceptibility to vulnerability; they restrain the region's populace adaptive capacity to climate changes and variability [2]-[4]. Besides increases in temperature, climate change in sub-Saharan Africa is expected to cause, increases in the incidence of extreme events such as droughts and floods [5]-[9], changes in rainfall intensity [10], increases in desertification and increased in drought frequencies [4] [11] [12].

Present research confirms that while crops would respond positively to elevated $\mathrm{CO}_{2}$ [13], the associated impacts of elevated temperatures, altered patterns of precipitation and possibly increased frequency of extreme events, droughts and floods. Taken all else as equal, these events will probably combine to depress crop yields and increase production risks [2]. Expected impacts include shortened or disrupted growing seasons, reductions in the area suitable for agriculture, and declines in agricultural yields in many regions of sub-Saharan Africa [9] [14]. Several studies have already revealed that a combination of increased rainfall variability and increasing ambient air temperatures will cause a significant decline in yields of major staple crops, particularly for maize [15]. 
In a recent work, Lobel et al. [16] used a data set of more than 20,000 historical maize trials in combination with daily weather data. It showed that for each degree day spent above $30^{\circ} \mathrm{C}$ maize yield was reduced by 1 percent under optimal rain-fed conditions, and by 1.7 percent under drought conditions. In a similar study, maize yield projections in Malawi found a decline of up to 20 percent in the next 50 years [16]. A similar study projected a decline of 10 to 57 percent by 2080 in Zimbabwe [6] [17], which is mainly due to increased rainfall variability. It is noted that many other factors contribute, but these projections allow to showcase the framework and if business as usual would prevail.

Climate change is emphasized as one of the major sources of challenge for food security, and livelihoods making the southern African region vulnerable to a variety of stresses. It is estimated that the livelihoods of nearly $70 \%$ of the region which depends on rain-fed agriculture, an activity that is characterized by small-scale, subsistence farms is affected [18] [19]. Due to its largely adverse effects on African agriculture and livelihoods, climate change is expected to have a negative impact on food security [9] [18] [20]. In a recent study, most farmers in Zambia are unable to afford certain alternatives, such as those of agro-forestry or conservation; they face difficulties in accessing markets due to poor road infrastructure, fluctuating market prices, high costs and late deliveries of farming inputs [21]. Coupled with the low presence of systematic early warning systems in place against natural hazards and disasters, it shows the adaptation capacity of farmers remains limited.

Most of the research on climate change impacts related to food in Africa, as evident in IPCC assessments, focuses on changes in crop yields and food production [9] [10] reported climate change impacts on the yield of maize by considering regional model across southern Africa. These authors experimented on several climate change scenarios and examined the sensitivity of maximized yields to shifting of sowing dates as a means of developing adaptation decisions by keeping yields as high as possible.

It is reported that with current climate change mitigation policies and related sustainable development practices, global GHG emissions will continue to grow over the next few decades [2]. The projected climate change and emission scenarios are well documented in the latest IPCC reports [2]. The various future storylines of GHG emission scenarios are expressed in terms of SRES scenarios [22]. The SRES scenarios, provided in [22], are grouped into four scenario families (A1, A2, B1 and B2) that represent alternative development pathways, covering a wide range of demographic, economic and technological driving forces and resulting GHG emissions. The emissions projections are widely used in the assessments of future climate change, as inputs to many recent climate change vulnerability and impact assessments.

For the assessment of climate change impact on agricultural productivity and yield, several models have been used. A number of these agricultural models are developed to analyse and model crop-soil-water interactions under different agro ecological and agronomic practices under rainfed systems as well as under irrigated conditions. Some of these crop models are: 1) Decision Support System for Agro technology Transfer (DSSAT) [23]; 2) Erosion Productivity Impact Calculator (EPIC) [24]; 3) Crop Environment Resource Synthesis (CERES) model [25]; 4) The Agricultural Production Systems Simulator (APSIM) [26]; 5) CROPWAT [27]; 6) Soil Moisture Accounting Crop-Specific (SMACS) model [28]; and 7) the CLICROP model [29].

Of the several crop models, the FAO CROPWAT and SMACS models can easily be adopted with very little field data demand. The latter has also been tested for the same study area for observed climatology of 42 years covering the period 1961-2002, under no-climate change conditions [28]. FAO's CROPWAT is a monthly crop model which considers daily rainfalls applied on selected days of each decade. SMACS is a daily-moisture accounting model adaptable for different crops, and externally coupled with daily rainfall and temperature generation model. Another advantage of the SMACS model is that it easily enables/allows external coupling with GCM outputs with possible disaggregation to daily values using weather generators.

Beyond impact assessment, the SMACS model can be used as a decision support system as it can also be used to calculate water balances such as actual crop ET, excess surface runoff and actual soil moisture besides yield and crop stress indicators. It is therefore suitable to evaluate and investigate the potential of and promote rainwater harvesting and conservation agriculture practices as potential adaptation measures. The water requirement of the crop at a given time of the growing season is calculated by multiplying the reference (Potential) evapotranspiration with a crop coefficient, whose values are published by FAO [27]. SMACS model is considered due to easy adaptability to simulate soil moisture balances, crop water demand and stress for current climatology as well as post climate change conditions.

In the SMACS model, all precipitation in excess of surface runoff (computed using the SCS curve number model [30], is assumed to infiltrate the soil surface. Soil water flow was modelled following the approach taken 
in the CERES models [25], in which water is immediately transferred downward in the soil profile if the amount of water entering the layer exceeds the layer's saturated water content. Water will then continue to drain from a layer until a drained water upper limit or field capacity is reached. Further water can be removed from the soil only through evaporation and transpiration. Soil evaporation is simulated by assuming a limiting water content to which soil evaporation can dry the soil, and that evaporative potential declines continuously as a function of soil water depth.

The ratio of actual transpiration (soil water uptake) to potential transpiration is used as the environmental indicator of water stress and yield potential [31]-[35]. In the crop models considered in the study (maize, sorghum and sunflower), water stress is assumed in the crops to affect growth by limiting photosynthesis in direct proportion to the ratio of actual to potential transpiration. The common approach for estimating crop yield reduction is based on FAO experience [36], which addressed the relationship between crop yield and water use by proposing a simple equation where relative yield reduction is linearly related to the corresponding relative reduction in evapotranspiration (ET) [36].

Future climate changes, as well as differences in climates from one location to another, may involve changes in climatic variability as well as changes in the means. In this study, a synthetic weather generator is used to systematically change the within-year variability of temperature and precipitation (and therefore also the interannual variability), without altering long-term mean values. For precipitation, both the magnitude and the qualitative nature of the variability can get manipulated. The synthetic daily weather series serve as input to the three crop simulation models.

\section{Study Area}

The study area is commonly known as the Pandamatenga Plains. It is located on the north-eastern edge of Botswana and is contiguous with the borders of Namibia, Zambia and Zimbabwe in the southeast. It also meets the confluence of the Chobe River with the Zambezi River. The area also extends with similar agro ecological settings in Zimbabwe (Figure 1), representing a number of farming communities in a number of districts.

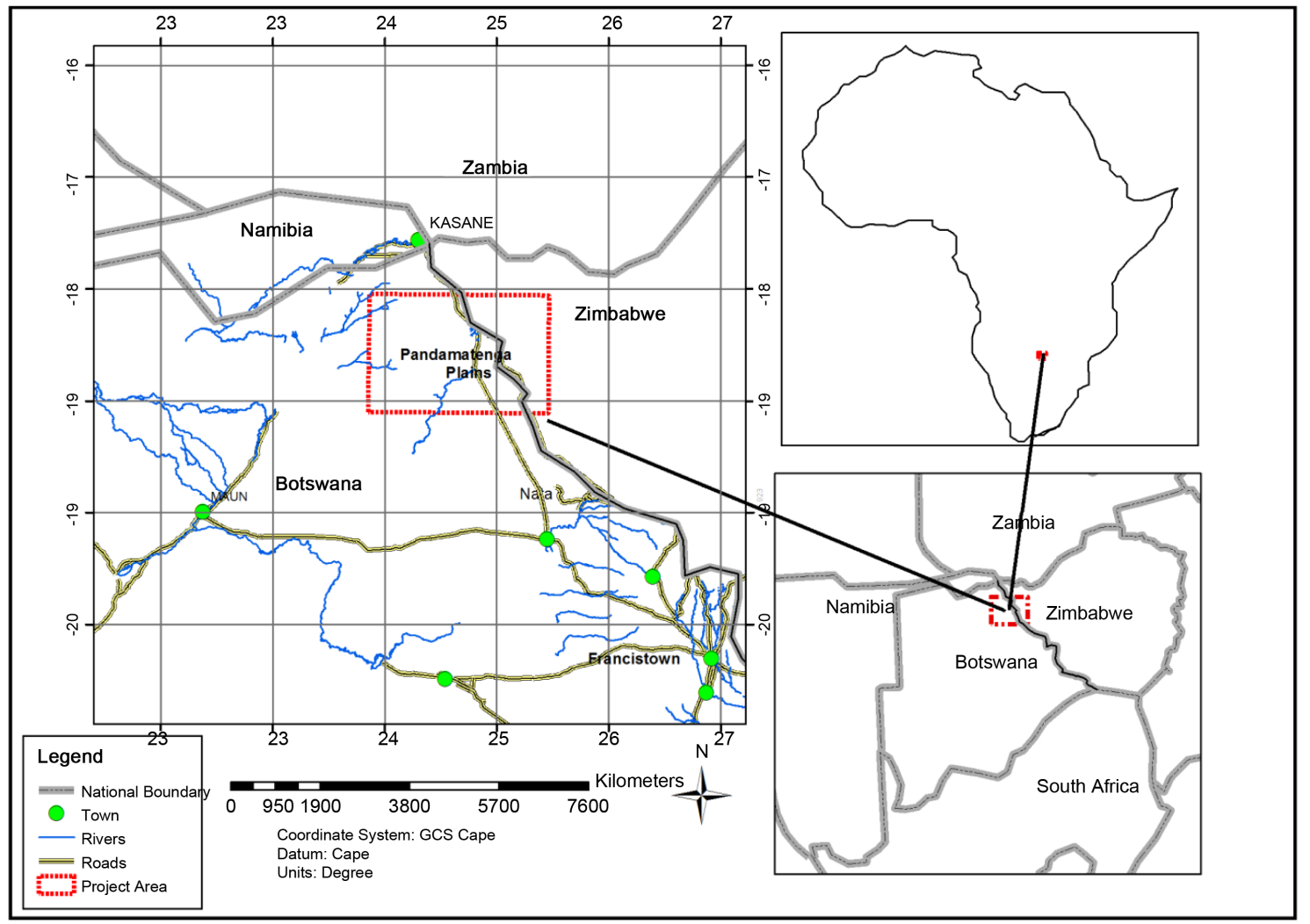

Figure 1. Location map of the study area. 
Due to its transboundary linkage and since it exhibits similar agro-ecological characteristics extending and covering Southern Zambia, eastern Namibia, western Zimbabwe and north-eastern Botswana, the site was considered as an ideal site for assessing the climate change impacts of rainfed farming systems. Furthermore, the study site is a vast agricultural area where rainfed agriculture is currently practiced.

The area is characterized by the presence of heavy clay soils. It is understood that during the rainy season they are liable to become sticky, waterlogged and poorly aerated, and they become hard during dry periods. They are reasonably fertile and are capable of retaining both water and nutrients [37]. Successful cultivation and good management in some areas have shown that these soils are able to make a significant contribution to food production. Because of low drainage, harvesting rainwater excesses can be practiced in such soil conditions.

The climate of the project area, like most of the north and south-eastern Botswana, is sub-tropical and semi-arid. The climate records at Kasane and Pandamatenga compiled by the Department of Metrological Services (DMS) have been available for the study. The monthly air temperature variation in the project area computed from 1971-2000 recorded data indicates a mean daily minimum and maximum temperature of $15^{\circ} \mathrm{C}$ to $29^{\circ} \mathrm{C}$, respectively. The highest temperatures are prevalent during November to March of the year while June and July experience the lowest temperatures.

Figure 2 shows the annual temperature variations and general trend in the daily maximum and minimum temperature data of Francistown, a nearby climatic station for the period 1971 to 2000 . Wind direction is normally easterly, north-easterly and south-easterly. The incidence of higher winds is greater around September, October and November with average speeds of above $180 \mathrm{~km} /$ day. Mean annual rainfall in general varies, with most rain falling during the summer months. Rainfall is characterized by short periods of heavy rain, which cause flush flooding. The men annual rainfall in the study area is generally about $550 \mathrm{~mm}$.

\section{Model Design and Data}

\subsection{State-of-the-Art in Agricultural Impacts of Climate Change}

Assessments of climate change impacts are especially challenging because they are subject to considerable uncertainties of climate predictions and the feedback mechanisms. Several studies highlighted the importance of precipitation, temperatures, soil moisture, and atmospheric $\mathrm{CO}_{2}$ concentrations in crop-soil-atmospheric interactions [13] [38] [39]. These components are projected to change significantly in the coming decades [2]. The knowledge gained in such experimental studies can be formalized in models, helping to structure the complex interactions, which can be purely conceptual, or quantitative [40].

One such approach is to apply crop models with simulation results of atmospheric general circulation models (GCMs). In the this study, MAGICC/SCENGEN climate predictions were adopted to study the regional and local climate and also analyse the wider variations among various GCM predictions embedded in MAGICC/ SCENGEN [41] and to consider the crop yield sensitivity by the various SRES and GCM scenarios. It was applied in the context of the local climate conditions of the Pandamatenga plains located in northern Botswana

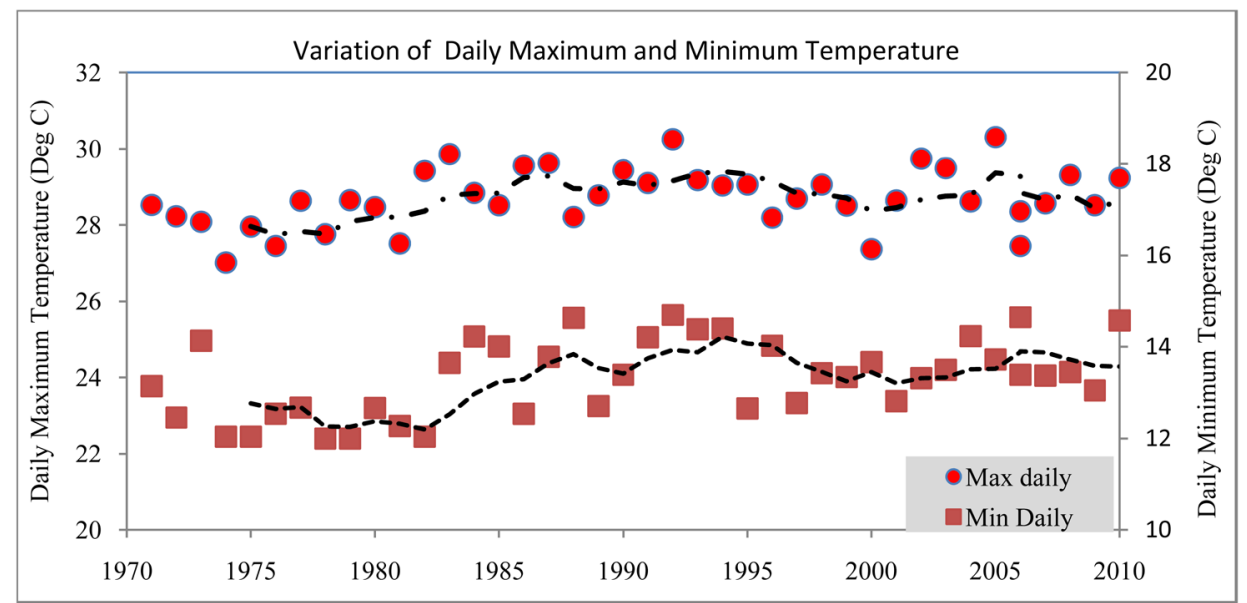

Figure 2. Annual variation of daily maximum and minimum temperature (1971- 2000) at Francistown station. The dashed lines indicate the mean values of 5 years temperature values. 
considering a square grid with a spatial resolution of $2.5^{\circ}$.

Wider variations among GCM predictions are generally common among climate predictions obtained from the various researches conducted by different organizations and researchers due to possible different in model assumptions, the mathematical model boundaries, climate forcing, etc. However, GCMs provide the most plausible regional climate change scenarios.

It was attempted to determine the climate change scenarios over the study area from various GCM simulations. Figure 3 shows changes in temperature in ${ }^{\circ} \mathrm{C}$ and change in precipitation in percentage form as given by the model for a $2.5^{\circ}$ square grid located with center at Latitude $21.25^{\circ} \mathrm{E}$, Longitude $28.75^{\circ} \mathrm{S}$ around the center of the catchments based on the SRES scenarios of A1B-A1M, which is the illustrative scenario adopted [41].

The coordinates a square area covering the study area were identified and the corresponding model output of simulated monthly climate scenarios were extracted for a set GCM and SRES scenarios. Figure 3 illustrate the variations in the predicted changes of precipitation and GCMS simulated by the climate model. Of which three scenarios are summarized in Table 1 simulated changes and temperatures for the 2050s at a $2.5^{\circ}$ square pixel centered at the Pilot area (around the center of the Pandamatenga Plains) from three selected GCM scenarios that were adopted as they typically present dry, moderate and wet conditions. Due to wide mix of the models and their prediction, the study was based on the following three scenarios. These are summarized in Table 1 and described as:

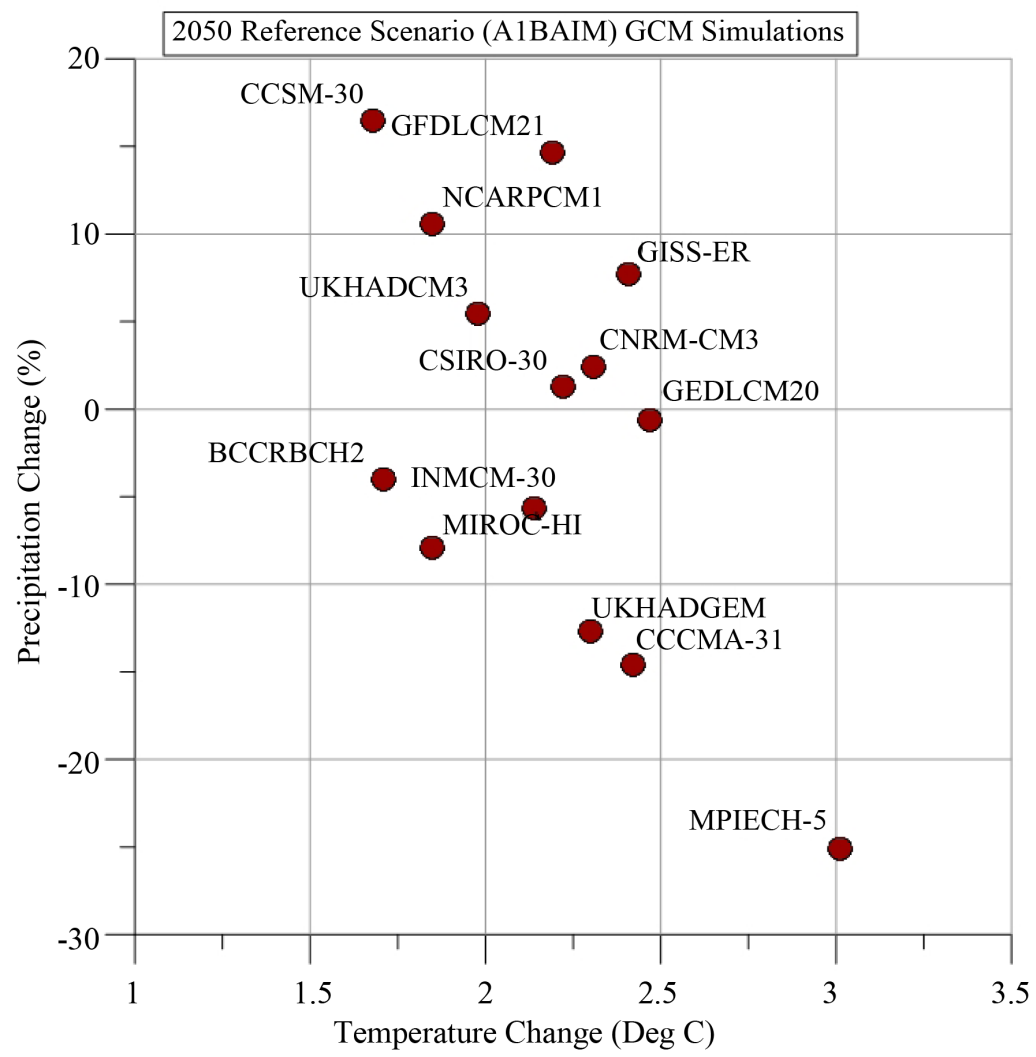

Figure 3. Comparison of GCM projections at a $2.5^{\circ}$ square GCM grid centered at Pandamatenga/Mid-Zambezi Basin (between $17.5^{\circ} \mathrm{S}-20^{\circ} \mathrm{S}$ and $\left.25^{\circ} \mathrm{E}-27.5^{\circ} \mathrm{E}\right)$.

Table 1. Projected changes in temperature and precipitation during the baseline period in the study area.

\begin{tabular}{cccc}
\hline GCM & Temperature change $\left({ }^{\circ} \mathrm{C}\right)$ & Precipitation change (\%) & Remark \\
\hline CCCMA-31 & 2.42 & -14.60 & Warm/Dry \\
GFDLCM21 & 2.19 & 14.70 & Warm/Wet \\
UKHADCM3 & 1.98 & 5.50 & Moderate \\
\hline
\end{tabular}


- Warm and wet conditions (Scenario 1). This is a typical condition represented by GFDLCM21.

- Warm and dry conditions (Scenario 2). This is a typical condition represented by CCCMA-31.

- Moderate conditions (Scenario 3). This is a typical condition represented by UKHADCM3.

\subsection{Yield Reduction and Climate Change Impacts on Rainfed Agriculture}

The impact of agricultural drought on crop production can be largely expressed by yield reduction. For this, yield reduction due to water deficiency was computed within SMACS model software. Yield reduction was calculated from water balance output combined with an empirical formula developed which recommends a formula for percentage yield reduction,

$$
Y_{r}=K_{y}\left(1-E_{a} / E_{p}\right) \times 100
$$

where $E_{a}$ is the actual evapotranspiration, $E_{p}$ is the total water requirement without water stress, and $K_{y}$ is a crop dependent stress indicator, which is known as the yield response factor.

Based on the analysis of an extensive amount of the available literature on crop-yield and water relationships and deficit irrigation, $K_{y}$ values of 1.25 for Maize, 0.9 for Sorghum and 0.95 for Sunflower were adopted from [36].

\subsection{Risk, Resilience and Reliability of Rainfed Agriculture}

To understand climate change and related impacts on rainfed agriculture, the investigation involved the study of sustainability of rainfed systems through soil moisture modelling and risk analysis of various crops using three indicators: risk, resilience, vulnerability indices. These factors are used as quantitative measures for assessment of soil moisture reliability and sustainability of rainfed systems, details of which are presented in [42].

There is clear evidence showing that besides moisture stress and soil fertility constraints often constitute the primary limiting factor to crop growth also in drylands [43]. Soil water stress can be assessed from crop-soilwater simulations of long-term meteorological variables especially using crop specific water accounting (SMACS) model [28]. More recent trend has been the assessment of degree of availability of soil moisture which is an integrating variable for the underlying hydroclimatic and agronomic factors of rainfed agricultural areas. The risk level for sustenance of rainfed systems can be determined as a probability at which the soil moisture $(S)$ drops below a given moisture threshold $\left(S_{\mathrm{WP}}+S_{a} \cdot p\right)$ during the crop's length of the growing period (LGP), $S_{a}=S_{\mathrm{FC}}-S_{\mathrm{WP}}$, which is the readily available moisture content i.e. soil moisture content at field capacity minus that at wilting point, and $p$ is the available soil moisture factor which is expressed as $p=\left(S-S_{W P}\right) / S_{a}$. The risk factor for the entire growing period (simulation period) of crops under rainfed conditions can be calculated as defined as:

$$
r[\%]=\frac{n}{T} \times 100 \%
$$

where $n$ is the number of days in which actual soil moisture $S$, drops below the critical soil moisture threshold $\left(S_{\mathrm{WP}}+S_{a} \cdot p\right)$ during the total number of days $(T)$ of the entire cropping period over all the entire years of simulation. In a period of years of analysis considered, $T$ in days becomes the product of the number of the simulated years and the length of the growing period (LGP) in days, which is assumed to be constant for each year. The risk factor here is the same as the probability of failure which refers to the proportion of days to the total number of cropping days in the entire number of years simulated, within which the simulated soil moisture drops below the amount which is set at $p$ times the readily available soil moisture content. If other agricultural conditions such as land management and nutrient availability are not altered, then this risk factor integrates the prevailing hydroclimatology, soil moisture availability and crop-soil-water conditions to assess sustainability of the crops cultivated under rainfed conditions.

Reliability and resilience have been widely used in water resources management to express the state of reservoir system [43], and these concepts have been adopted in this study to explain the state of soil moisture its availability for sustenance of crop growth in the SMACS model. Reliability is a measure of frequency or probability that a system is in a satisfactory state meeting a given criterion. Resiliency generally indicates a measure of how quickly a system recovers from failure once failure has occurred. The computational scheme for these indices in this study is almost similar to that of water management applications used in [44]-[46], which are spe- 
cifically tailored for analysing soil moisture stress and the associated risks and sustainability of rainfed systems.

Defining a criterion $(C)$ as the minimum required soil moisture from a rainfed agricultural system, the daily soil moisture depth $\left(S_{t}\right)$ can be classified as a satisfactory state $(A)$ or a failure state $(B)$, i.e.,

$$
\text { If } S_{t} \geq C\left\{\begin{array}{l}
\text { then } \quad S_{t} \in A \text { and } Z_{t}=1 \\
\text { else } S_{t} \in B \text { and } Z_{t}=0
\end{array}\right.
$$

where $Z_{t}$ is a generic indicator variable. The daily available moisture content $\left(S_{t}\right)$ simulated in the SMACS model was evaluated against criterion and, thus, system failure occurs when soil moisture is below the criterion at any given day i.e. satisfactory state and failure if otherwise. The criteria $C$ used is $C=S_{\mathrm{WP}}+S_{a} \cdot p$.

\section{Results and Analysis}

\subsection{Coupling Disaggregated Climate Data with Crop Model}

In order to simulate the impact of changed climate simulated by GCMs on the soil water balances, a simplified procedure was used through external coupling of the interaction between monthly weather generation models, the climate models and the crop-water balance model (SMACS). Soil retention parameters (permanent wilting point, field capacity and available moisture content), as well as crop growth factors and crop calendars, for the crops considered in the study were used as input to the SMACS model. The SMACS model simulates soil moisture, actual evapotranspiration, runoff, and indices such as crop yield, risk, reliability, resilience based on simulations at daily time steps from disaggregated inputs of precipitation and computed potential evapotranspiration. These indices in impact assessment of climate change on agriculture resources.

A weathergenerator was used as a procedure of incorporating natural variability in the analysis involves employing an ensemble of scenarios of climate variables that are formulated by stochastic hydrologic methods [47]-[50]. Weather generators are statistical methods that base on observed historical records of climate variable to generate long-term series of synthetic climatic data by preserving statistical properties of the observed data. In these models, the variance across an ensemble at a time step represents the temporal variability of the hydrologic variables and similar approaches have been applied in hydrological impact studies of climate change [48]-[50].

The monthly changes in temperature and precipitation obtained from SCENGEN as climate change scenarios of 2100s were disaggregated to reconstruct the time series of monthly temperature and precipitation from the end of the baseline period-extending from 2001 up to 2100. They were then made inputs to the crop water balance model, SMACS [28]. Time series of synthetic daily weather values exhibiting the same means as, but different variability from, the base climates were constructed using the approach presented in [51] [52]. The monthly mean values for the baseline period are used to adjust the mean values of the changed climate values. Under increase of GHG concentrations, GCMs can predict long-term climatic changes with some degree of certainty. Thus, the perturbed/changed climate provided by GCMs for month $j$ is treated as $\Delta(j)$. Thus, in a changing climate, the future climatic mean $S^{*}(j)$ say for 2100 can be given by:

$$
S^{*}(j)=(1+\Delta(j)) S(j)
$$

where $S(j)$ represents the baseline climate for month $j, S^{*}(j)$ is the future mean value and $\Delta(j)$ is the change relative to the present value of the climatic variable (fraction). The monthly change $\Delta(j)$ is considered as the GCM output which is available for grids covering the globe for various periods say 2100s, $N$ years from the current climatic period.

In order to incorporate the year to year variability of these changes, the mean value of the changes is assumed to increase proportionally up to the number of years of simulation - for example $-N$ years up to the 2100 s for which GCM changes are considered. The changes in each month $j$ which are linearly varying for each year $i$ and designated by $\Delta(i, j)$, the corresponding monthly value of the future climate $S^{*}(i, j)$ is calculated as:

$$
S^{*}(i, j)=\left[1+\Delta(i, j) \frac{i}{N}\right] S(j) \quad j=1,12
$$

Equation (5) can be used to generate daily time series for $N$ years with linearly increasing/decreasing monthly means. In order to assess soil-water balances, the possible transient responses with respect to these transient climatic variables should be accommodated. This approach is an ideal condition as it is a linear assumption in 
which the monthly climatic variable is assumed to increase or decrease in each year $i$ constantly and consistently for $N$ years (Equation (5)).

Therefore, the monthly climate averages/values in the case of the precipitation or adjusted harmonic mean values for the temperature, are used in the weather generator model to obtain modified mean values. Then the variability of historical values is used to determine the daily time series data. For precipitation data, the Markov chain model transition matrices were used to determine the dry-wet day sequences and for the precipitation depths for wet days were determined from probability distribution model, a calibrated Weibull model developed for the region [53]. Details of this procedure used in daily rainfall and temperature weather generation is presented in literature [53] [54]. An in house computer program using FORTRAN was written to develop the weather generator and couple it with the SMACS model.

\subsection{Yield Reduction and Climate Change Impacts on Rainfed Agriculture}

Yield reductions in common grains grown in the study area have been simulated. These common crops are maize, sorghum and sunflower, which are cultivated widely by farming communities in the study area. The crop coefficients and soil coefficients assuming vertisols throughout two lithological layers have been assumed for the purpose of this study.

A summary of yield reductions for time slices of 2001-2050 simulated by the three GCMs in comparison with the baseline scenario are presented in Figure 4. It appears that the yield reductions of all the cultivars considered, maize, sorghum and sunflower, in general are predicted by CCCMA-31 scenario compared to the other scenarios i.e. the UKHDCM3 and the GFDLCM21 scenarios.

In almost 50 percent of the years considered during simulation period of 2001-2050, the yield reductions are above 50 percent (Figure 4), and in general sorghum appears to exhibit lower reduction compared to maize followed by sunflower.

\subsection{Risk and Climate Sensitivity}

The study attempted to establish and understand the degree of susceptibility of crop to failures in terms of soil moisture availability to meet the evapo-transpirative demands of crops studied. Using the SMACS model, the following indices, namely risk, resilience and reliability were used to investigate the available moisture failure rates in rainfed conditions, where rainfed agriculture is practiced in the study site. In this study, daily simulations from climatic data of 1971-2000 were made for the study area, considering commonly grown crops: maize, sunflower, and sorghum.

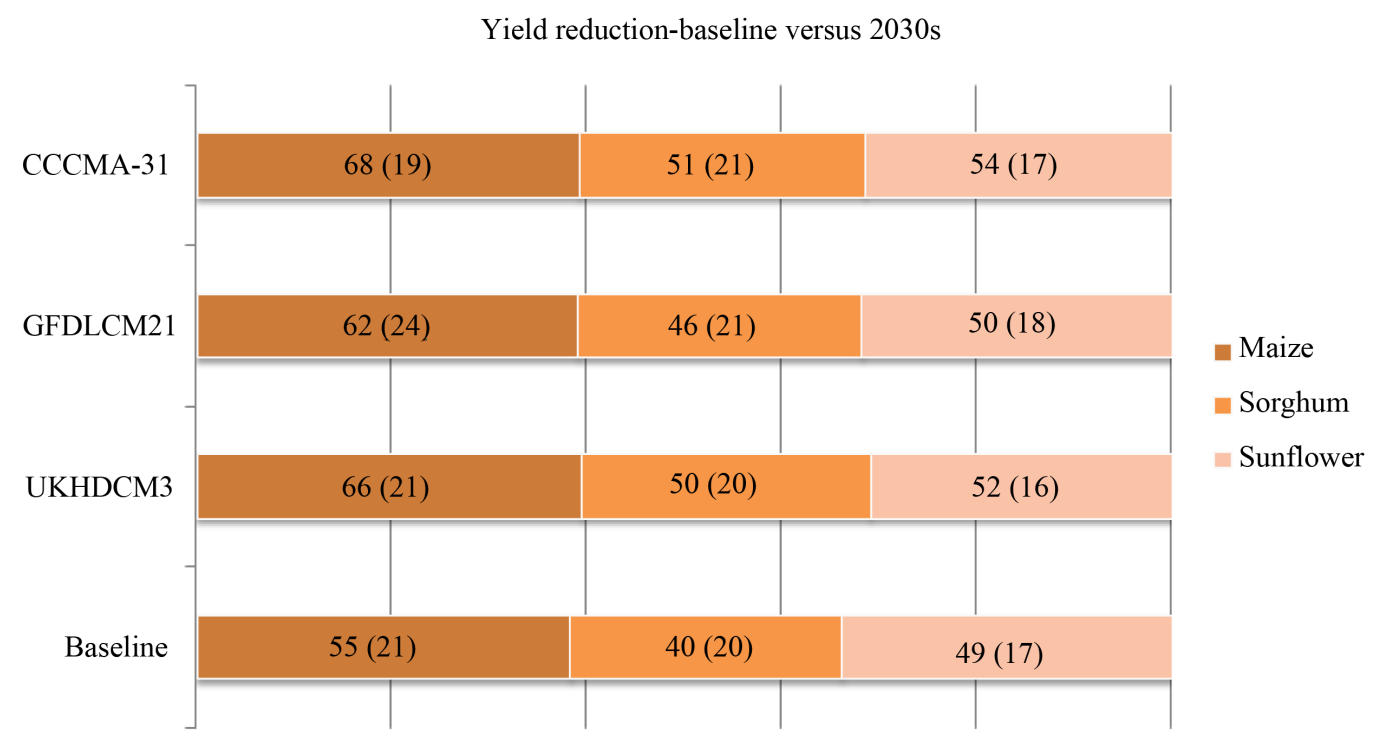

Figure 4. Projected mean percentage yield reductions under baseline and three GCM scenarios. The standard deviations are given in parentheses. 
Risk, reliability and resilience of maize simulated from the entire 1971-2000 daily record and taking the current sowing dates and actual cropping length, at available soil moisture factor, $p=30 \%$ for Pandamatenga Plains is shown in Table 2. The corresponding indices for the post climate change scenarios are also computed. Percentage pie charts for these sustainability indices with available soil moisture factor, $p=30 \%$ are presented for the baseline period as well as the three climate changes scenarios in Figure 5.

The results of analysis of risk, resilience and reliability of rainfed agriculture can be used as indicators of vulnerability and the extent to which mitigation measures can be taken, such as by adjusting sowing dates for the perceived changes in the climate and weather system. In similar studies [31] observed that maize yields declines could be offset by shifting of sowing dekads/dates as a means of developing adaptation decisions by keeping maize yields as high as possible.

\subsection{Mitigating Risk and Potential for Excess Rainwater Harvesting}

Another mitigation potential to be explored is harvesting of excess runoff during days where precipitation excesses are prevalent above the infiltration capacity and moisture holding capacity of soils. The potential for harvesting excess storm runoff in the rainfed agricultural fields of the study site is investigated. Results are

Table 2. Comparison of sustainability indicators of risk, reliability and resilience for the baseline climatology.

\begin{tabular}{cccc}
\hline Indicator & & 1971-2000 (Baseline Period) \\
\cline { 2 - 4 } & Maize & Sunflower & Sorghum \\
Risk (\%) & 0.94 & 4.87 & 9.85 \\
Reliability (\%) & 99.1 & 95.1 & 39.1 \\
Resilience (\%) & 38.5 & 32.9 & 3 \\
\hline
\end{tabular}

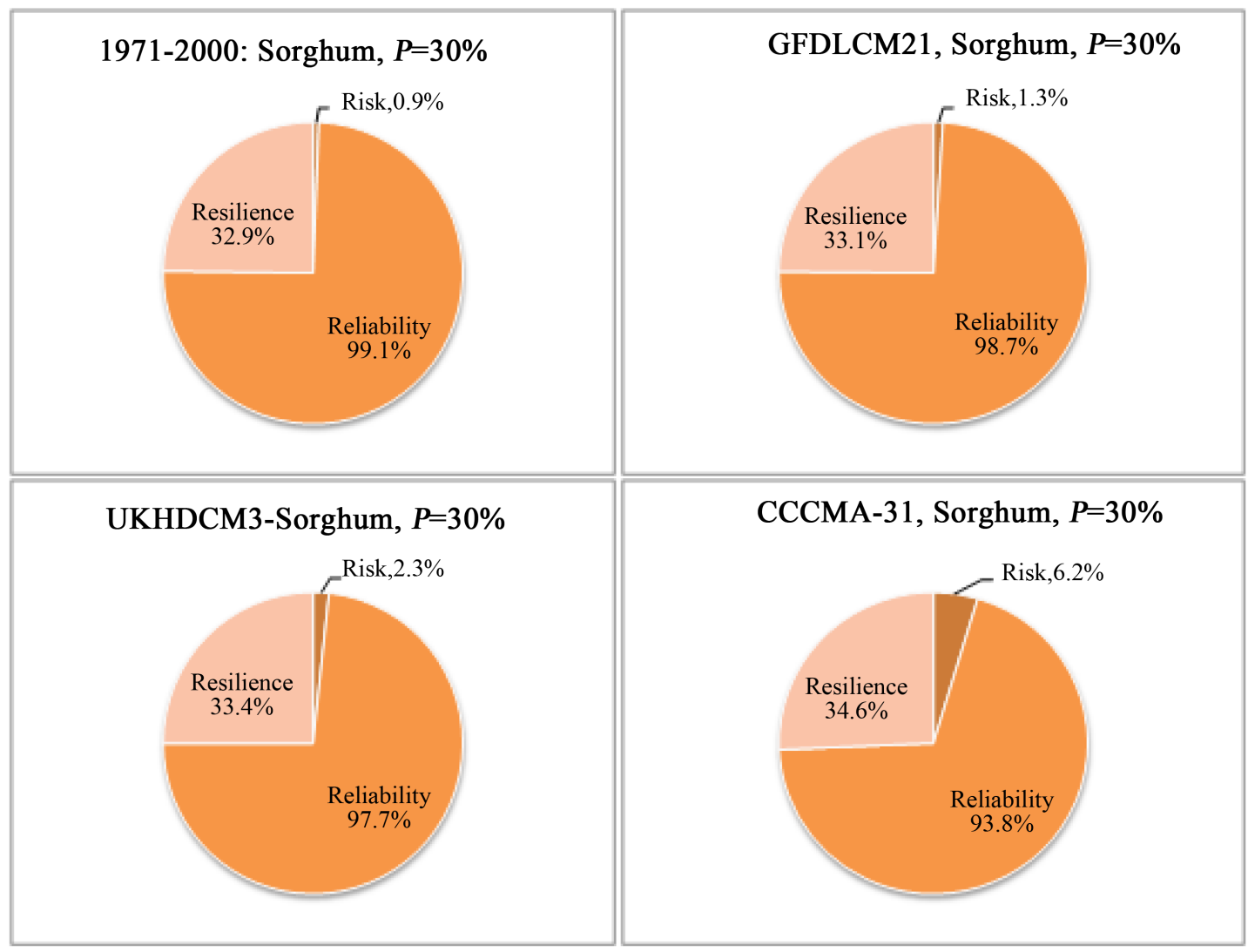

Figure 5. Risk, reliability and resilience of sorghum under rainfed conditions with available soil moisture factor, $p=30 \%$. 
summarized in Table 3. The corresponding runoff potential and percentile duration curves are presented for the baseline period as well as the three climate changes scenarios in Figure 6.

It can be noted that the excess runoff harvesting potential in only sorghum cropping system is relatively higher than the maize or sunflower cases. However, in the mixed farming case, relatively better harvesting potential can be harnessed reaching as far as an average of $22 \mathrm{~m}^{3} \cdot \mathrm{ha}^{-1} \cdot \mathrm{d}^{-1}$ say in more than $15 \%$ of the days of the combined cropping period in days.

\subsection{Soil Moisture Enhancement}

Relevant mitigation practices might entail enhancing the available soil moisture availability to full utilization by crops. The potential to be explored is the harvesting of excess runoff during days where precipitation excesses are prevalent above the infiltration capacity and soil moisture holding capacity of soils.

The potential for enhancement of soil moisture in the rainfed agricultural fields of the study site is investigated. Results are summarized in Table 4. The corresponding soil moisture content for the post climate change scenarios, as percentile duration curves are presented for the baseline period as well as the three climate changes scenarios is presented in Figure 7.

\section{Discussion}

The yield response to changes in precipitation variability can depend on the qualitative nature of the variability and it is used to understand the impacts of climate changes. The results also suggest that the current atmospheric general circulation models (GCMs) yield inconsistent results concerning changes in mean precipitation at particular locations, and the sign and magnitude of any change in the interannual variability is even less clear. However, the present results suggest that the qualitative nature of these changes may be a significant determinant of important agricultural impacts and which can help to devise mitigation mechanisms and develop adaptation plans.

The study also suggested that there are opportunities to improve agriculture water productivity and implement integrated soil-water management strategies in rain-fed farming systems. This is so important especially for the development of mitigation measures and adaptation measures in similar farming systems. For instance where livelihood improvement, food security and productivity increment is sought in rainfed agriculture-practicing areas of the region in general and in the study area considered, the Pandamatenga plains, in particular. These will also have a direct linkage in the vast lower rainfall and rainfed plains extending to southern Zambia, northern Namibia and northwestern Zimbabwe.

Table 3. Direct runoff in mm as percentage of days exceeded that can be harvested for the baseline climatology.

\begin{tabular}{|c|c|c|c|c|c|c|c|c|}
\hline \multirow{3}{*}{$\begin{array}{c}\text { Indicator: } \\
\% \text { No of days exceeding }\end{array}$} & \multicolumn{4}{|c|}{$1971-2000$} & \multicolumn{4}{|c|}{$1971-2000$} \\
\hline & \multicolumn{4}{|c|}{ Baseline [mm] } & \multicolumn{4}{|c|}{ Baseline $\left[\mathrm{m}^{3} \cdot \mathrm{ha}^{-1} \cdot \mathrm{d}^{-1}\right]$} \\
\hline & Maize & Sorghum & Sunflower & Average & Maize & Sorghum & Sunflower & Average \\
\hline $10 \%$ & 2.79 & 4.39 & 2.95 & 3.56 & 28 & 44 & 29 & 36 \\
\hline $15 \%$ & 1.70 & 2.32 & 2.03 & 2.25 & 17 & 23 & 20 & 22 \\
\hline $20 \%$ & 0.69 & 1.31 & 1.04 & 1.29 & 7 & 13 & 10 & 13 \\
\hline
\end{tabular}

Table 4. Soil moisture in mm as percentage of days exceeded per cropping season for the baseline climatology.

\begin{tabular}{|c|c|c|c|}
\hline \multirow{2}{*}{$\begin{array}{c}\text { Indicator: } \\
\% \text { No of days exceeding }\end{array}$} & \multicolumn{3}{|c|}{ 1971-2000 (Baseline period) } \\
\hline & Maize & Sunflower & Sorghum \\
\hline $70 \%$ & 227 & 42 & 307 \\
\hline $80 \%$ & 219 & 38 & 298 \\
\hline $90 \%$ & 211 & 34 & 289 \\
\hline
\end{tabular}



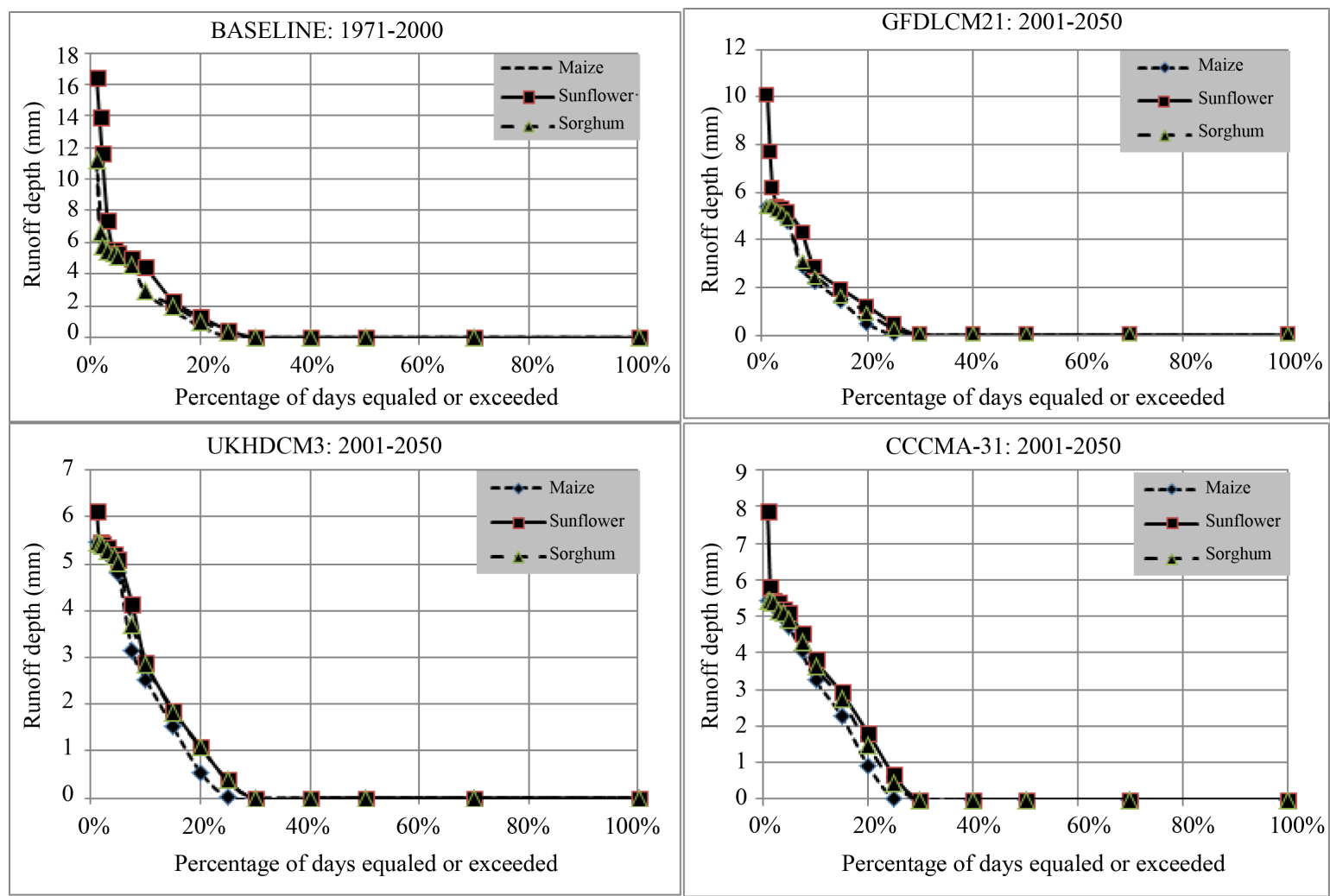

Figure 6. Rainwater harvesting potential and runoff depth under rainfed conditions.
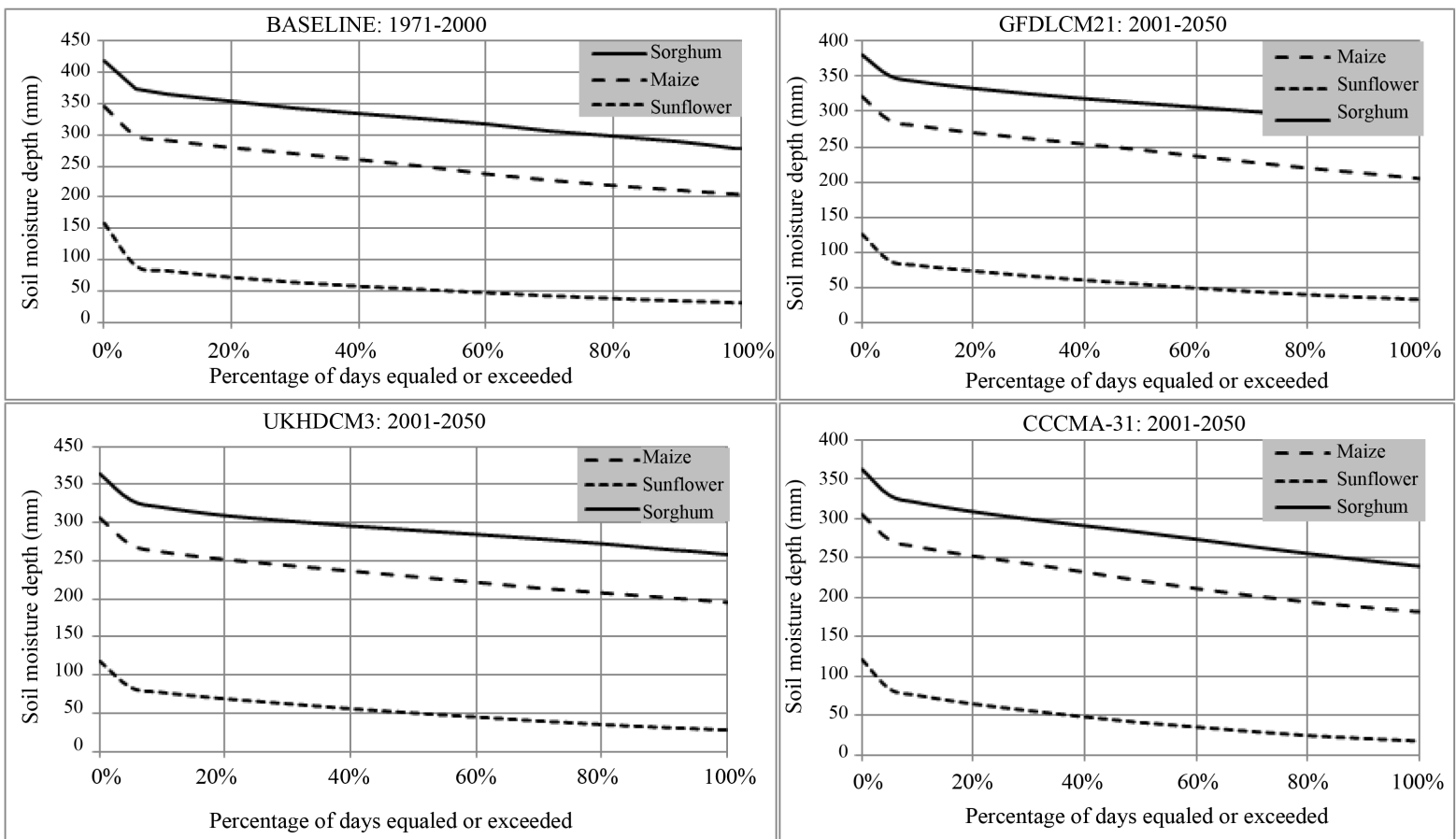

Figure 7. Soil moisture availability under rainfed conditions.

Integrated soil-water management strategies could include: 1) strengthening of conservation tillage to improve soil-water productivity and land fertility; 2) improving near real-time weather forecasting and advisory 
services to support farmers to adjust cropping pattern and planting dates of cultivars; 3) encouragement and incentive measures for effectively use available rainwater and harvest excess runoff; and 4) strengthening contribution to awareness and public policy processes in an effort demonstrate the potential benefits of developing adaptation strategies in terms of the socio-economic, economic diversification benefits and ultimately improvement of food security of a nation or the region at large.

In a recent survey conducted in the study area including farming communities in three districts in southern Zambia (Chogwe, Chisamda and Chipembi Districts), it was found that a mix of various Conservation Farming and Climate Adaptation Practices [55]. The farmers have developed local and indigenous knowledge systems and they also appreciate how improvements in conservation farming, water harvesting, water access and climate resiliency could help them protect their deteriorating agricultural and livestock yields in their community. These practices included: 1) Dry-season land preparation using minimum tillage; 2) Crop residue retention; 3) Seeding and input application in fixed planting stations; 4) Nitrogen-fixing crop rotation; 5) Infield water conservation; 6) Crop-livestock system for soil fertility; 7) Crop-livestock system for income generation; and 8) Mixed farming of maize with soybeans, groundnuts, etc. These practices are there for possible adoption by other communities in similar agro-ecological conditions, if they are given the means and support them in agricultural productivity and household food security enhancement.

\section{Conclusions}

As the regional impacts of climate change are wider than the local situation of this study area, this then highlights the need for outscaling of the mitigation measures. This outscaling becomes imperative to joint regional efforts of climate change mitigation and adaptation efforts especially in southern Africa [55]. These mitigation and adaptation mechanisms highlighted above can be considered for outscaling with the domain of Climate Smart Agriculture [56], in which the modeling approach and tool can be harnessed as a decision support tool. This will help understand and assess the various rainfed farming systems and interventions employed to improve productivity and enhance resilience of smallholder farmers against impacts of climate change and variability. In turn, the interventions can be used to assess the contribution of and effectiveness of achieving maximum net benefits of mitigation, adaptation and emission reduction.

A typical modelling framework recommended in a study that attempts to understand climate change, agriculture and adaptation in a farming ecosystem is illustrated in Figure 8. For this, more computer simulations and research needs to be undertaken to address and understand the linkages of climate change, agriculture and adaptation including the complexity of feedback mechanisms that need to be incorporated across various spatial and temporal scales.

Sustainable rural development research has taken different approaches to the integration of management technologies in the search for a more holistic agricultural system, examples being Integrated Natural Resources Management (INRM), Integrated Water Resources Management (IWRM), Integrated Soil and Nutrient (Soil Fertility) Management (ISFM), Integrated Crop and Livestock Management (ICLM), Integrated Pest Management (IPM). These concepts are very common practices for farmers in southern Africa, who traditionally have

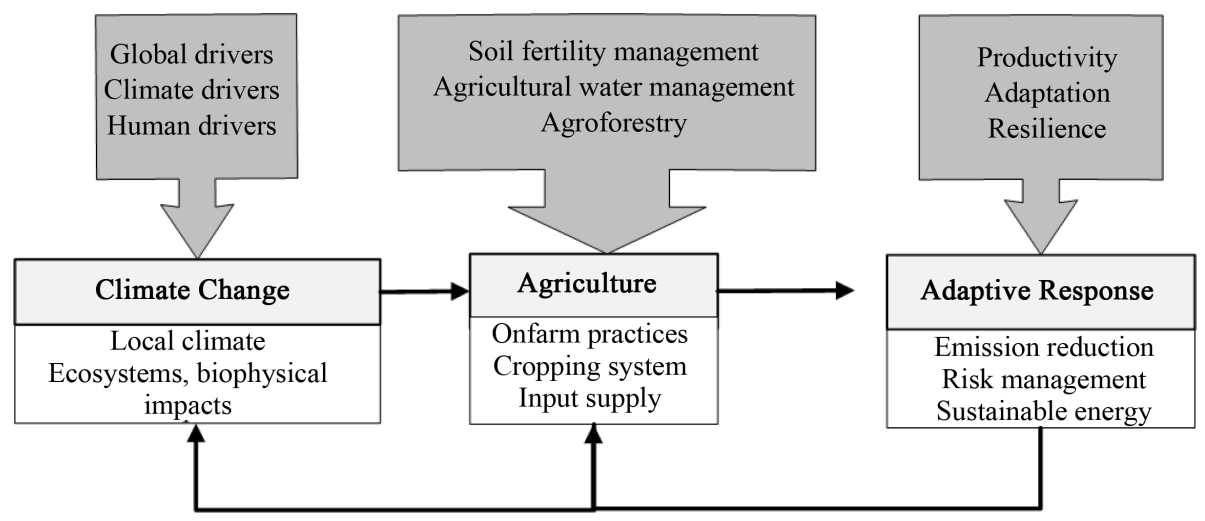

Figure 8. A typical modelling framework to understand climate change, agriculture and adaptation in a farming ecosystem. 
implemented various mixed farming systems and farm practices appropriate to the local ecology. In order to enhance agricultural sustainability, a number of good localized examples of INRM exist [57], such as the farming systems research approach instituted by FAO [58]. This approach basically aims at simultaneously improving livelihoods, agro-ecosystem resilience, agricultural productivity and the provision of environmental services by augmenting social, physical, human, natural and financial capital [59].

It is also essential to note that a range of fundamental natural resources, including land, water, air, biological diversity including forests, fish, etc., provide the indispensable base for agricultural production system and sustenance of agricultural ecosystems. Due to population growth and expansion of agricultural activities, the physical and functional availability of natural resources is diminishing [59]. The latter can be attributed to loss of biodiversity, deforestation, loss of soil health, and water shortage. Given the multifunctional nature of agriculture, it is critical to consider linkages across ecosystems in which agricultural systems are embedded, as these have important implications for the resilience or vulnerability of these systems. These linkages between natural resource use and the social and physical environment across space and time are important issues for scaling out and the dissemination of agricultural knowledge, science and technology, with significant implications for sustainable development and the mitigation of adverse impacts [59].

\section{Acknowledgements}

This research was supported by CCARDESA's CCARPASA Project, jointly implemented by University of Botswana and Continental Consultants based in Gaborone, Botswana. The authors also appreciate the support of the University of Botswana for funding the daily weather generation model development under Research Project Grant No: R025, "Development of Daily Precipitation Model for Botswana". The authors also acknowledge the Department of Metrological Services for providing daily rainfall time series data used in the weather generation modeling, and the Ministry of Agriculture for proving soil and related information.

\section{References}

[1] SADC (2011) Climate Change Adaptation in SADC: A Strategy for the Water Sector. SADC Secretariat, Gaborone, Botswana, $40 \mathrm{p}$.

[2] Meehl, G.A., Stocker, T.F., Collins, W.D., Friedlingstein, P., Gaye, A.T., Gregory, J.M., Kitoh, A., Knutti, R., Murphy, J.M., Noda, A., Raper, S.C.B., Watterson, I.G., Weaver, A.J. and Zhao, Z.-C. (2007) Global Climate Projections. In: Solomon, S., Qin, D., Manning, M., Chen, Z., Marquis, M., Averyt, K.B., Tignor, M. and Miller, H.L., Eds., Climate Change 2007: The Physical Science Basis, Contribution of: Working Group I to the Fourth Assessment Report of the Intergovernmental Panel on Climate Change, Cambridge University Press, Cambridge, 747-846.

[3] Davidson, O., Halsne, S.K., Huq, S., Kok, M., Metz, B., Sokona, Y. and Verhagen, J. (2003) The Development and Climate Nexus: The Case of Sub-Saharan Africa. Climate Policy, 3, S97-S113. http://dx.doi.org/10.1016/j.clipol.2003.10.007

[4] Reich, P.F., Numben, S.T., Almaraz, R. and Eswaran, H. (2001) Land Resources Stress and Desertification in Africa. Agro-Science, 2, 1-10.

[5] Richard, Y., Fauchereau, N., Poccard, I., Rouault, M. and Trzaska, S. (2001) 20th Century Droughts in Southern Africa: Spatial and Temporal Variability, Teleconnections with Oceanic and Atmospheric Conditions. International Journal of Climatology, 21, 873-885. http://dx.doi.org/10.1002/joc.656

[6] New, M., Hewitson, B., Stephenson, D.B., Tsiga, A., Kruger, A., Manhique, A., Gomez, B., Coelho, C.A.S., Masisi, D.N. and Kululanga, E. (2006) Evidence of Trends in Daily Climate Extremes over Southern and West Africa. Journal of Geophysical Research, 111, D14102. http://dx.doi.org/10.1029/2005jd006289

[7] Milgroom, J. and Giller, E. (2013) Courting the Rain: Rethinking Seasonality and Adaptation to Recurrent Drought in Semi-Arid Southern Africa. Agricultural Systems, 118, 91-104. http://dx.doi.org/10.1016/j.agsy.2013.03.002

[8] Ngongondo, C.S., Li, L., Gong, L.B., Xu, C.-Y. and Alemaw, B.F. (2013) Flood Frequency under Changing Climate in the Upper Kafue River Basin, Southern Africa: A Large Scale Hydrological Model Application. Journal of Stochastic Environmental Research and Risk Assessment, 27, 1883-1898. http://dx.doi.org/10.1007/s00477-013-0724-z

[9] Niang, I., Ruppel, O.C., Abdrabo, M.A., Essel, A., Lennard, C., Padgham, J. and Urquhart, P. (2014) Africa. In: Barros, V.R., Field, C.B., Dokken, D.J., Mastrandrea, M.D., Mach, K.J., Bilir, T.E., Chatterjee, M., Ebi, K.L., Estrada, Y.O., Genova, R.C., Girma, B., Kissel, E.S., Levy, A.N., MacCracken, S., Mastrandrea, P.R. and White, L.L., Eds., Climate Change 2014: Impacts, Adaptation, and Vulnerability. Part B: Regional Aspects. Contribution of Working Group II to the Fifth Assessment Report of the Intergovernmental Panel on Climate Change, Cambridge University Press, Cambridge, 1199-1265. 
[10] Thomas, D.S.G., Twyman, C., Osbahr, H. and Hewitson, B. (2007) Adaptation to Climate Change and Variability: Farmer Responses to Intraseasonal Precipitation Trends in South Africa. Climatic Change, 83, 301-322. http://dx.doi.org/10.1007/s10584-006-9205-4

[11] Stringer, L.C., Dyer, J.C., Reed, M.S., Dougill, A.J., Twyman, C. and Mkwambasi, D. (2009) Adaptations to Climate Change, Drought and Desertification: Local Insights to Enhance Policy in Southern Africa. Environmental Science and Policy, 12, 748-765. http://dx.doi.org/10.1016/j.envsci.2009.04.002

[12] Alemaw, B.F., Onema, J.M.K. and Love, D. (2013) Regional Drought Severity Assessment at a Basin Scale in the Limpopo Drainage System. Journal of Water Resource and Protection, 5, 1110-1116. http://dx.doi.org/10.4236/jwarp.2013.511116

[13] Ainsworth, E.A. and Long, S.P. (2005) What Have We Learned from 15 Years of Free-Air $\mathrm{CO}_{2}$ Enrichment (FACE)? A Meta-Analytic Review of the Responses of Photosynthesis, Canopy Properties and Plant Production to Rising $\mathrm{CO}_{2}$. New Phytologist, 165, 351-371. http://dx.doi.org/10.1111/j.1469-8137.2004.01224.x

[14] Muller, C., Cramer, W., Hare, W.L. and Lotze-Campen, H. (2011) Climate Change Risks for African Agriculture. Proceedings of the National Academy of Sciences of the United States of America, 108, 4313-4315. http://dx.doi.org/10.1073/pnas.1015078108

[15] Dixon, R.K., Smith, J. and Guill, S. (2003) Life on the Edge: Vulnerability and Adaptation of African Ecosystems to Global Climate Change. Mitigation and Adaptation Strategies for Global Change, 8, 93-113. http://dx.doi.org/10.1023/A:1026001626076

[16] Lobell, D.B., Burke, M.B., Tebaldi, C., Mastrandrea, M.D., Falcon, W.P. and Naylor, R.L. (2008) Prioritizing Climate Change Adaptation Needs for Food Security in 2030. Science, 319, 607-610. http://dx.doi.org/10.1126/science.1152339

[17] Fischer, G., Shah, M., Tubiello, F.N. and Van Velhuizen, H. (2005) Socio-Economic and Climate Change Impacts on Agriculture: An Integrated Assessment, 1990-2080. Philosophical Transactions of the Royal Society B, 360, 20672083. http://dx.doi.org/10.1098/rstb.2005.1744

[18] Challinor, A., Wheeler, T., Garforth, C., Crauford, P. and Kassam, A. (2007) Assessing the Vulnerability of Food Crop Systems in Africa to Climate Change. Climatic Change, 83, 381-399. http://dx.doi.org/10.1007/s10584-007-9249-0

[19] World Bank (2009) Agriculture and Rural Sector South Asia: Shared Views on Development and Climate Change. World Bank, Washington DC, 97-107.

[20] Connolly-Boutin, L. and Smit, B. (2015) Climate Change, Food Security, and Livelihoods in Sub-Saharan Africa. Regional Environmental Change. http://dx.doi.org/10.1007/s10113-015-0761-x

[21] Makondo, C.C., Chola, K. and Moonga, B. (2014) Climate Change Adaptation and Vulnerability: A Case of Rain Dependent Small-Holder Farmers in Selected Districts in Zambia. American Journal of Climate Change, 3, 388-403. http://dx.doi.org/10.4236/ajcc.2014.34034

[22] Nakićenović, N. and Swart, R. (2000) Special Report on Emissions Scenarios: A Special Report of Working Group III of the Intergovernmental Panel on Climate Change. Cambridge University Press, Cambridge, 599 p.

[23] Jones, J.W. (1986) Decision Support System for Agrotechnology Transfer. Agrotechnology Transfer, 2, 1-5.

[24] Williams, J.R. (1995) The EPIC Model. In: Singh, V.P., Ed., Computer Models of Watershed Hydrology, Water Resources Publications, Highlands Ranch, 909-1000.

[25] Jones, C.A. and Kiniry, J.R. (1986) CERES-Maize: A Simulation Model of Maize Growth and Development. Texas A\&M University Press, College Station, 194 p.

[26] McCown, R.L., Hammer, G.L., Hargreaves, J.N.G., Holzworth, D. and Huth, N.I. (1995) APSIM-An Agricultural Production System Simulation Model for Operational Research. Mathematics and Computers in Simulation, 39, 225231. http://dx.doi.org/10.1016/0378-4754(95)00063-2

[27] FAO (1992) Cropwat-A Computer Program for Irrigation Planning and Management. FAO Irrigation and Drainage Publications, No. 46, Rome.

[28] Alemaw, B.F., Chaoka, T.R. and Totolo, O. (2006) Investigation of Sustainability of Rain-Fed Agriculture through Soil Moisture Modeling in the Pandamatenga Plains of Botswana. Physics and Chemistry of the Earth, 31, 960-996. http://dx.doi.org/10.1016/j.pce.2006.08.009

[29] Fant, C. (2009) CliCrop: A One-Dimensional Model to Calculate Water Stress on Crops. University of Colorado at Boulder, UMI Dissertations Publishing, Ann Arbor.

[30] SCS (1985) National Engineering Handbook, Section 4: Hydrology, Soil Conservation Service. USDA, Washington DC.

[31] Crespo, O., Hachigonta, S. and Tadross, M. (2011) Sensitivity of southern African Maize Yields to the Definition of Sowing Dekad in a Changing Climate. Climate Change, 106, 267-283. 
http://dx.doi.org/10.1007/s10584-010-9924-4

[32] De Wit, C.T. (1958) Transpiration and Crop Yields. Agricultural Research Reports 64.6 Pudoc, Wageningen, 88 p.

[33] Hanks, R.J. (1983) Yield and Water-Use Relationships: An Overview. In: Taylor, H.M., Jordan, W.R. and Sinclair, T.R., Eds., Limitations to Efficient Water Use in Crop Production, American Society of Agronomy, Madison, 393-411.

[34] Nonhebel, S. (1994) The Effects of Use of Average Instead of Daily Weather Data in Crop Growth Simulation Models. Agricultural Systems, 44, 377-396. http://dx.doi.org/10.1016/0308-521X(94)90194-K

[35] Simane, B., van Keulen, H. and Stol, W. (1994) Application of a Crop Growth Model (SUCROS-87) to Assess the Effect of Moisture Stress on Yield Potential of Durum Wheat in Ethiopia. Agricultural Systems, 44, 337-352. http://dx.doi.org/10.1016/0308-521X(94)90226-6

[36] Doorenbos, J. and Kassam, A.H. (1979) Yield Response to Water. FAO Irrigation and Drainage Paper No. 33, Rome.

[37] Ministry of Agriculture of Botswana (1990) Pandamatenga Development Study. Main Report-Annex B-Hydrology and Main Drainage. Arup-Atkins. Ministry of Agriculture, Gaborone.

[38] Iglesias, A., Quiroga, S. and Diz, A. (2011) Looking into the Future of Agriculture in a Changing Climate. European Review of Agricultural Economics, 38, 427-447. http://dx.doi.org/10.1093/erae/jbr037

[39] Ainsworth, E.A. (2008) Rice Production in a Changing Climate: A Meta-Analysis of Responses to Elevated Carbon Dioxide and Elevated Ozone Concentration. Global Change Biology, 14, 1642-1650. http://dx.doi.org/10.1111/j.1365-2486.2008.01594.x

[40] Hillel, D. and Rosenzweig, C. (2010) Handbook of Climate Change and Agroecosystems: Impacts, Adaptation, and Mitigation. Imperial College Press, London, 440 p.

[41] Wigley, T.M.L. (2008) MAGICC/SCENGEN 5.3 User Manual. NCAR, Boulder.

[42] Alemaw, B.F. (2012) Resilience, Reliability and Risk Analyses of Maize, Sorghum and Sunflower in Rain-Fed Systems Using a Soil Moisture Modeling Approach. Agricultural Sciences, 3, 114-123. http://dx.doi.org/10.4236/as.2012.31015

[43] Klaij, M.C. and Vachaud, G. (1992) Seasonal Water Balance of a Sandy Soil in Niger Cropped with Pearl Millet, Based on Profile Moisture Measurements. Agricultural Water Management, 21, 313-330. http://dx.doi.org/10.1016/0378-3774(92)90053-Y

[44] Hashimoto, T., Stedinger, J.R. and Loucks, D.P. (1982) Reliability, Resiliency, and Vulnerability Criteria for Water Resource System Performance Evaluation. Water Resources Research, 18, 14-20. http://dx.doi.org/10.1029/WR018i001p00014

[45] Maier, H.R., Lence, B.J. Tolson, B.A. and Foschi, R.O. (2001) First-Order Reliability Method for Estimating Reliability, Vulnerability, and Resilience. Water Resources Research, 37, 779-790. http://dx.doi.org/10.1029/2000WR900329

[46] Fowler, H.J., Kilsby, C.G. and O’Connell, P.E. (2003) Modeling the Impacts of Climatic Change and Variability on the Reliability, Resilience, and Vulnerability of a Water Resource System. Water Resources Research, 39, 1222. http://dx.doi.org/10.1029/2002WR001778

[47] Apipattanavis, S., Podestá, G., Rajagopalan, B. and Katz, R.W. (2007) A Semiparametric Multivariate and Multisite Weather Generator. Water Resources Research, 49, 7205-7220.

[48] Grantz, K., Rajagopalan, B., Clark, M. and Zagona, E. (2005) A Technique for Incorporating Large-Scale Climate Information in Basin-Scale Ensemble Streamflow Forecasts. Water Resources Research, 41, 1-14. http://dx.doi.org/10.1029/2004WR003467

[49] Gebretsadik, Y., Strzepek, K. and Schlosser, C.A. (2014) A Hybrid Approach to Incorporating Climate Change and Variability into Climate Scenario for Impact Assessments. World Institute for Development Economics Research, WIDER Working Paper 2014/112, 1-18.

[50] Yates, D., Gangopadhyay, S., Rajagopalan, B. and Strzepek, K. (2003) A Technique for Generating Regional Climate Scenarios Using a Nearest-Neighbor Algorithm. Water Resources Research, 39, 1-15. http://dx.doi.org/10.1029/2002wr001769

[51] Riha, S.J., Wilks, D.S. and Simoens, P. (1996) Impact of Temperature and Precipitation Variability on Crop Model Predictions. Climatic Change, 32, 293-311. http://dx.doi.org/10.1007/bf00142466

[52] Wilks, D.S. (1992) Adapting Stochastic Weather Generation Algorithms for Climate Change Studies. Climatic Change, 22, 67-84. http://dx.doi.org/10.1007/BF00143344

[53] Alemaw, B.F. and Chaoka, T.R. (2008) A Parametric Daily Precipitation Model Application in Botswana. Botswana Journal of Technology, 17, 41-47.

[54] Alemaw, B.F. and Chaoka, T.R. (2003) A Continental Scale Water Balance Model: A GIS-Approach for Southern Africa. Physics and Chemistry of the Earth, 28, 957-966. http://dx.doi.org/10.1016/j.pce.2003.08.040 
[55] CCARDESA (2014) Enhancing Evidence-Based Climate Change Adaptation Research and Policy for Agriculture in Southern Africa, CCARPASA Project, Final Report. CCARDESA Secretariat, Gaborone, 70.

[56] FAO (2010) Climate-Smart Agriculture-Policies, Practices and Financing for Food Security, Adaptation and Mitigation. UN Food and Agriculture Organization (FAO), Rome, 41.

[57] Palm, C.A., Vosti, S.A., Sanchez, P.A. and Ericksen, P. (2005) Slash-and-Burn Agriculture: The Search for Alternatives. Columbia University Press, New York.

[58] Norman, D.W., Worman, F.D., Siebert, J.D. and Modiakgotla, E. (1995) The Farming Systems Approach to Development and Appropriate Technology Generation. Food and Agriculture Organization of the United Nations, Rome. http://www.fao.org/docrep/v5330e/v5330e00.HTM.

[59] McIntyre, B.D., Herren, H.R., Wakhungu, J. and Watson, R.T. (2009) International Assessment of Agricultural Knowledge, Science and Technology for Development (IAASTD): Global Report. Island Press, Washington DC, 590. 